\title{
HYBRID FORECASTING OF DAILY RIVER DISCHARGES CONSIDERING AUTOREGRESSIVE HETEROSCEDASTICITY
}

\author{
Elena Peksová Szolgayová ${ }^{1,2}$, Michaela Danačová ${ }^{*}$, Magda Komorniková ${ }^{4}$ and Ján Szolgay ${ }^{3}$
}

\begin{abstract}
It is widely acknowledged that in the hydrological and meteorological communities, there is a continuing need to improve the quality of quantitative rainfall and river flow forecasts. A hybrid (combined deterministic-stochastic) modelling approach is proposed here that combines the advantages offered by modelling the system dynamics with a deterministic model and a deterministic forecasting error series with a data-driven model in parallel. Since the processes to be modelled are generally nonlinear and the model error series may exhibit nonstationarity and heteroscedasticity, GARCH-type nonlinear time series models are considered here. The fitting, forecasting and simulation performance of such models have to be explored on a case-by-case basis. The goal of this paper is to test and develop an appropriate methodology for model fitting and forecasting applicable for daily river discharge forecast error data from the GARCH family of time series models. We concentrated on verifying whether the use of a GARCH-type model is suitable for modelling and forecasting a hydrological model error time series on the Hron and Morava Rivers in Slovakia. For this purpose we verified the presence of heteroscedasticity in the simulation error series of the KLN multilinear flow routing model; then we fitted the GARCH-type models to the data and compared their fit with that of an ARMA - type model. We produced one-stepahead forecasts from the fitted models and again provided comparisons of the model's performance.
\end{abstract}

\section{Address}

1 Na Veselí 22, 14000 Prague, Czech Republic,

2 formerly at The Centre for Water Resource Systems, Vienna Universtity of Technology, Vienna, Austria

3 Dept. of Land and Water Resources Management, Faculty of Civil Engineering, Slovak University of Technology, Slovakia

1 Dept. of Mathematics, Faculty of Civil Engineering, Slovak University of Technology, Slovakia

* Corresponding author: michalela.danacova@stuba.sk

Key words

- Morava and Hron Rivers,

- KLN multilinear flow routing model,

- Simulation error,

- GARCH model.

\section{INTRODUCTION}

Basically, there are two main areas for the application of a time series analysis to hydrological data, i.e., simulation and predictions (forecasts). Simulations, i.e., the stochastic generation of synthetic records sufficing the fitted model, are mainly used for long-term water resources design projects (such as for reservoir designs, water supply capacity expansion projects or determining the risk of failure (or reliability) of irrigation or hydroelectric systems). Here, reliability of the system means the probability "that a system will perform the required function for a specified period of time under stated conditions" (Koutsoyiannis, 2005). The stochastic generation of synthetic records, which should be able to produce longer series than the measured records of data that are statistically indistinguishable from the historical data, has a long tradition in hydrology (e.g., Srikanthan and McMahon, 1980). Such longer series (although they do not contain more statistical information) contain pattern fluctuations not observed 
in the measurements needed for risk-based designs. In addition, other justifications of stochastic approaches exist, such as efforts to explain and forecast long-term fluctuations of time series, including the attempt to explain certain fluctuations such as the Hurst phenomenon (e.g., Elek and Márkus, 2004; Fendeková et al., 2014; Szolgayová et al., 2014).

Another important field where time series models are applied is in hydrological forecasting. It is widely acknowledged in the hydrological and meteorological communities that there is a continuing need to improve the quality of quantitative rainfall and river flow forecasts with different time steps (long-term forecasts for strategic management, seasonal forecasts for mid-term optimizations, and short-term forecasts for operational control and risk management (see, e.g., Pappenberger et al., 2005) for various water resources management problems (such as the safety of the drinking water supply from reservoirs, hydroelectric power generation, flood control, flood risk management, etc. (Arduino et al., 2005). Approaches used for river flow forecasting cover a wide range of different methods from deterministic (usually conceptual water balance models) to stochastic approaches (mainly in the time series domain). In the recent past a so-called hybrid (combined deterministic-stochastic) modelling approach was proposed that tries to combine the advantages offered by both methods by modelling the system dynamics with a deterministic model and the forecasting error series with a data-driven model in parallel. Analyzing the structure of the error series of deterministic hydrological models and forecasting these with data-driven models allows, for an improvement of the overall forecasting performance and, given that a time series model will be used as a data-driven approach, for estimates of the overall output uncertainties (see, e.g., Komorníková et al., 2008).

The ability to evaluate the uncertainties associated with a hybrid forecast is especially welcome, since this important information not only permits assessing the quality of the prediction, but can also serve as an input to operational actions and decisions conditioned on the distribution of the forecasted values (Todini, 2004). In such a hybrid scheme stochastic models used for generating artificial time series can in turn be applied for forecasting during real-time operations of water resources systems. This clearly shows that proper attention has to be paid to the identification of the proper type of stochastic processes, which may subsequently be adequately described by time series models.

In this paper nonlinear time series models of the GARCH class are suggested for forecasting hydrological flood-routing model error time series. We will concentrate on verifying whether the use of a GARCH-type model is suitable for modelling time series of errors resulting in a different (conceptual) model applied to the runoff data (i.e., creating a component of a hybrid model) in Slovakia. We can produce one-step-ahead forecasts from the fitted models and compare the forecasting performance of nonlinear time series models with that of linear error series models, since there is limited knowledge of their predictive capabilities concerning the particular problem of forecasting modelling error series.

The structure of the paper is as follows: in chapter 2 we provide a brief overview of various approaches and recent developments in nonlinear time series analysis in hydrology. In chapter 3, we introduce basic definitions, the GARCH models and the statistical tests applied to the data analysis in this paper. In chapter 4 we delineate some specifications of the rivers and geographical areas on which the data was modelled. We also give a short description of the conceptual models used to obtain the error time series. Chapter 5 contains the actual data analysis. Chapter 6 summarizes what has been accomplished and includes concluding remarks.

\section{NONLINEAR TIME SERIES ANALYSIS IN HYDROLOGY}

Among the existing models for time series predictions, linear autoregressive integrated moving average types of models (ARMA, PARMA, ARIMA, SARIMA etc.) have been among the most applied models in hydrology and have been used to predict hydrological variables till the present (e.g., Pekárová et al., 2009; Valipour, et al., 2013; Wang et al., 2015; Valipour, et al., 2015; Moeni et al., 2017). In general, however, applications of such time series models generally focus on modelling and predicting the mean behaviour or the first moment of the variable. These models are usually insufficient for capturing all the properties of the hydrological processes controlling the temporal variations of hydrological variables (Modarres and Ouarda, 2013) and especially those of forecasting error series. The processes to be modelled in hydrology are, in general, nonlinear (Wang et al., 2006); in addition, model error series may exhibit nonstationarity and heteroscedasticity. Therefore, the frequently used linear models originating from the classical Box-Jenkins methodology perform sub-optimally and have to be reconsidered and substituted for by approaches which take that in consideration.

Recently, several types of non-linear time series models (e.g., TAR, TARMA, SETAR, LSTAR, ATAR), which have been investigated in both the econometric and statistical literature, have also been shown to offer potential for explaining both the nonlinear behaviour of modelled hydrological time series and giving information on the forecast uncertainties (e.g., Tamea et al., 2005; Amendola, 2003; Wang et al., 2005; Liu and Chen 2007; Komorník et al., 2006; Chen et al., 2008; Komorníková et al., 2008; Valent et al., 2011).

In the time series domain (Generalized) Autoregressive Conditional Heteroscedasticity models (ARCH, GARCH) are widely used in finance to deal with heteroscedastic data. The theoretical aspects of the models were first introduced by Engle (1982) and developed by Bollerslev (1986). The modified ARCH model was further developed into models such as Nelson's EGARCH model (1991).

Thus far, compared to linear models, only a few attempts to apply these new types of models have been reported in hydrology. We will introduce these models later on; here, we are giving some examples of their recent use. Tol (1996) fitted a GARCH model for the conditional variance and the conditional standard deviation, in conjunction with an $\mathrm{AR}(2)$ model for the mean, to model daily mean temperatures. Wang et al. (2005) proposed an ARMA-GARCH error model to capture the ARCH effect present in daily streamflow series, as well as to preserve seasonality in the variances of the residuals. Chen et al. (2008) tried to combine the ARCH, TAR and TARMA models to explain the streamflow of the wet season in Taiwan. Elek and Márkus (2008) analysed a conditionally heteroscedastic GARCH-type model, which is different from the more commonly used autoregressive moving average-generalized autoregressive conditionally heteroscedastic (ARMA-GARCH) processes, with a daily water discharge series observed along the Rivers Danube and Tisza in Hungary. Otache et al., (2012) used streamflow data (both daily and monthly) of the River Benue, Nigeria, to critically look at the subject of Autoregressive Conditional Heteroscedasticity $(\mathrm{ARCH})$ and the volatility of streamflow processes. Modarres and Ouarda (2013) studied the advantages of a GARCH model against a linear ARIMA model by investigating three classes of the GARCH approach, namely the Power GARCH, Threshold GARCH and Exponential GARCH models, which use daily streamflow time series of the Matapedia River, Quebec, Canada. Modarres and Ouarda (2014) developed 
univariate and multivariate GARCH models for drought conditional variance-covariance, or volatility-covolatility, relationships with atmospheric indices.

These new types of non-linear time series models were shown to offer potential for explaining both the nonlinear behaviour of a modelled time series and giving information on the forecast uncertainty. Wang et al. (2005) and Chen et al. (2008) also showed the advantage of univariate GARCH models over linear models. However, as pointed out by Amendola (2003), nonlinear time series structures have often led to good fitting performances, but the good fitting results of nonlinear models do not guarantee an equally good forecasting performance (Chatfield, 2001). Indeed, more recently, Modarres and Ouarda (2013) indicated that the GARCH model does not exhibit superiority over seasonal autoregressive moving average models for modelling rainfall time series except for removing heteroscedasticity from the residuals of the linear model (Modarres and Ouarda, 2014). Therefore, the development of nonlinear time series models for hybrid modelling frameworks and for modelling time series in hydrological applications needs to be case based. The investigation of model properties and performances has to be thoroughly tested under various conditions for their future practical applications and physiographic conditions. Another challenge for research with these purely data-driven models is how to choose an appropriate model class for forecasting problems with respect to the hydrological conditions and processes in a catchment.

\section{THE KLN FLOOD ROUTING MODEL}

In this study we have investigated the presence of heteroscedasticity in the KLN flood-routing model simulation error data series with daily frequencies from two measuring stations from the Hron (Brehy station) and Morava (Záhorská Ves station) Rivers in Slovakia. The setup and parametrisation of the KLN model, which was used to produce the series of errors, are taken from flow routing studies accomplished in a $\mathrm{PhD}$ thesis by Danáčová (2008). A brief description of the rivers, followed by a short introduction of the hydrological model used for supplying the simulated discharge series (the error series) analysed in this study, is given here; details on both sites and the model can be found, e.g., in Szolgay et al. (2006), Danáčová and Szolgay (2007), or Szolgay at al. (2008).

The KLN model belongs to a group of so-called conceptual models, which is between black-box models, which produce outputs based purely on calibrating measured input data, and physically- based models, which use theoretical physical and mathematical dependencies, thus minimizing the need for calibration. In a conceptual model, the modelling problem is divided into basic subproblems, which are treated separately and usually on a lumped (catchment or river reach) scale. In the KLN model the river is broken into sub-reaches; each is modelled by a linear reservoir with one parameter.

This model consists of a series of $\mathrm{n}$ linear reservoirs in series, each with the time constant (storage coefficient) k (see Fig. 1). The storage $\mathrm{S}_{\mathrm{i}}$ and discharge $\mathrm{Q}_{i}$ relationship of the $\mathrm{i}$-th reservoir in the series is considered to be $S_{i}=k$. $Q_{i}$. The input to the cascade is given by a vector I. Here, each reservoir is allowed to have an external input $\mathrm{I}_{\mathrm{i}}$. In the first reservoir of the series, $\mathrm{I}_{1}$ accounts for the inflow to the cascade at the cross section of the inlet of the modelled reach. In the subsequent reservoirs, $\mathrm{I}_{\mathrm{i}}$ stands for the lateral inflow (or withdrawal) of water into (from) the corresponding reservoir along the reach.

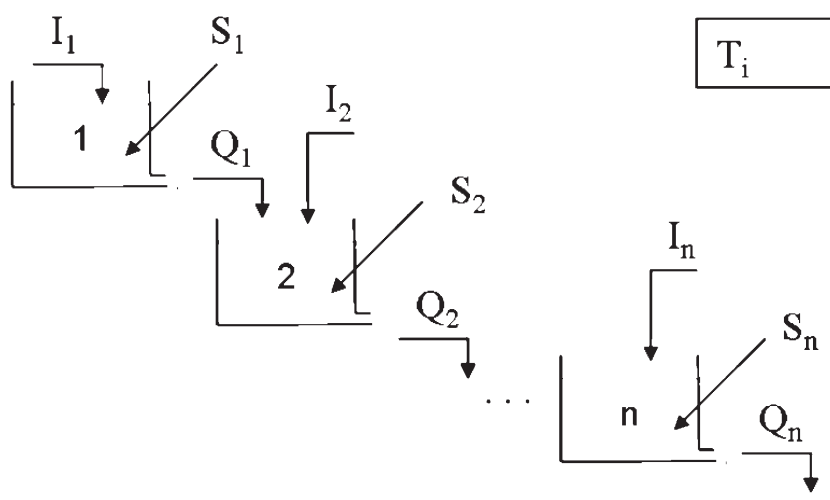

Fig. 1: The multilinear cascade of linear reservoirs - KLN model.

All the inputs I to the cascade are considered to be constant during the sampling interval $(\mathrm{a} ; \mathrm{a}+1)$ of the length $\mathrm{T}$ (the input hydrograph is schematised as a stepwise constant function of time (e.g., the mean flow during the sampling interval). The governing state-space equations of the model (the state equation and the outflow equation), $\mathrm{S}(\mathrm{a}+1)=\mathrm{F}(\mathrm{S}(\mathrm{a}) ; \mathrm{I}(\mathrm{a} ; \mathrm{a}+1), \mathrm{k}) ; \mathrm{Q}(\mathrm{a}+1)=$ $\mathrm{G}(\mathrm{S}(\mathrm{a}+1) ; \mathrm{k})$. The functions $\mathrm{F}(.) ; \mathrm{G}($.$) are exactly given, e.g., in$ Szolgay (2004). The multilinear version of the discrete cascade model was used to generate the data for this thesis. In this extended version the state vector $\mathrm{S}(\mathrm{a}+1)$ at the end of the computational step $(a+1 ; a)$ is considered the initial condition for the next computational step $(a+2, a+1)$; then, the value of $k$ is re-estimated. Here, as proposed in Szolgay (2004), empirical information on the variation of the travel-time of flood peaks with the input discharge in the modelled reach was used to directly estimate the time variability of time parameter $\mathrm{k}$ of the cascade of the reservoirs (Danáčová, 2008).

\section{MODELS AND METHODS APPLIED TO ANALYZE THE FLOW ROUTING MODEL ERROR SERIES}

When talking about time series of interest in hydrology, one has to distinguish between natural data, such as runoff, rain or temperatures, and time series which originate from other models, i.e., model error series. The latter case has scarcely been a point of research, but the interest in analyzing this kind of data is increasing (e.g., Svetlíková, 2008). Here, we will be observing a series of errors resulting from the KLN flood routing models calibrated for the Morava and Hron Rivers.

\subsection{Time series models}

In general, we will consider here the time series as a sequence of random variables

$$
\mathrm{X}=\left(\mathrm{X}_{\mathrm{t}}, \mathrm{t} \in \mathrm{T}\right) \quad \mathrm{T}=\mathrm{N} \text { or } \mathrm{Z}
$$

From now on, let $\mathrm{T}$ denote the set of time indices. As indicated above, $\mathrm{T}=\mathrm{N}$ or $\mathrm{Z}$.

The hydrological time series consists in general of the following components:

Trend: The long-term component that represents the growth or decline in a time series over an extended period of time.

Seasonal component: A pattern of change in data that repeats itself from year to year. 

trend.

Cyclical component: The wavelike fluctuation around the

Irregular component: The residuals of the values of the time series after the other components have been removed.

Since the data modelled in hydrology come from very different settings starting with the frequency of observations (as already stated, annual, monthly, daily or subdaily), being correlated and having non-linear behaviour, sometimes showing a long memory effect, and depending on geographical and climatic conditions as well and thus having different properties from case to case, a vast amount of research is being done to find suitable mathematical representations for all possible conditions (for a review, see, e.g., Salas, 1980; Kutsoyannis, 2005). In hybrid modeling schemes, which are some of the oldest model classes, the family of autoregressive moving average models was applied (e.g., Szolgay, 1985; Szolgay and Minárik, 1992). Here, these models will be used as a basis for comparison to the GARCH and EGARCH models of the model error time series.

The linear autoregressive moving average $(\operatorname{ARMA}(p, q))$ is given by:

$$
X_{t}=\sum_{i=1}^{p} b_{i} X_{t-i}+\sum_{j=1}^{q} a_{j} \epsilon_{t-j}+\epsilon_{t}
$$

where $\epsilon_{t} \sim$ white noise $\left(0, \sigma^{2}\right)$, and the autoregressive integrated moving average $(\operatorname{ARIMA}(p, q, d))$ models are defined as

$$
\left(1-\sum_{i=1}^{p} a_{i} B^{i}\right)(1-B)^{d} X_{t}=\left(1+\sum_{i=1}^{q} b_{i} B^{i}\right) \epsilon_{t}+\epsilon_{t}
$$

where $B$ is the backshift operator, such that $B^{k} X_{t}=X_{t-k}, k \in Z \backslash\{0\}$, and $\mathrm{d} \in \mathrm{N}$ is the so-called order difference, which completes the family of models suggested by Box and Jenkins (1976).

These have been followed in hybrid forecasting by numerous other model classes, such as regime-switching models in, e.g., Svetliková (2008); Komorníková et al., (2008). This study presents results concerning the possibility of using GARCH-types of models for such purposes. The basic idea is that unlike all of the models described above, the variance of the time series is not constant. Thus far, only a few attempts to apply GARCH-type time series models have been reported in the hydrological time series literature; none of these have been in the hybrid forecasting context. Figure 2 presents a sample error series of the KLN model on

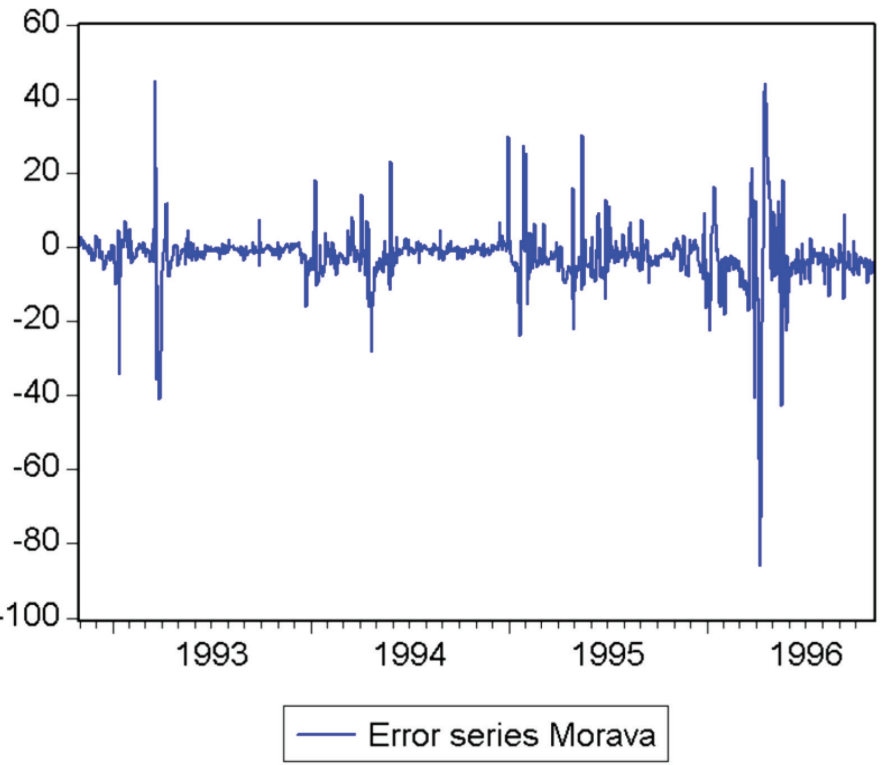

Fig. 2 Sample error series of the KLN model on the Morava River; simulation error in $\mathrm{m}^{3} / \mathrm{s}$. the Morava River. In this particular case the general property of the hydrological processes seems to be heteroscedascity, since the rise of discharges is rainfall driven (a highly nonlinear, chaotic and intermittent process), and decreases in discharges are ruled by the damping effects of the water storage in the driven system (catchment or river reach), which filters and smoothes the pulselike behaviour of the inputs. That this behaviour is present in a hydrological model error series can be explained by the fact that the modelling/routing and forecasting of floods (pulse-like rising discharges) is a more demanding task than that of forecasting droughts (slowly decreasing flows).

A time series is a $\mathbf{G A R C H}(\mathbf{p}, \mathbf{q})$ time series if it suffices that

$$
\begin{gathered}
X_{t}=\sigma_{t} e_{t} \\
\sigma_{t}^{2}=\alpha_{0}+\sum_{i=1}^{q} \alpha_{i} X_{t-i}^{2}+\sum_{j=1}^{p} \beta_{j} \sigma_{t-j}^{2}
\end{gathered}
$$

Where $e_{t}$ is an i.i.d. white noise with variance 1 and mean $0, \alpha_{0}>0, \alpha_{\mathrm{i}}, \beta_{\mathrm{i}} \in \mathrm{R}^{+}, \forall \mathrm{i}$, and $\mathrm{e}_{\mathrm{t}}$ is independent of $\mathrm{X}_{(\mathrm{t}-\mathrm{k})}, \mathrm{k} \in \mathrm{N}, \forall \mathrm{t}$.

When $\mathrm{p}=0, \mathrm{X}_{\mathrm{t}}$ is a so-called $\mathrm{ARCH}(\mathrm{q})$ time series (Kraus and Neuhaus, 2004).

The conditional variance equation (5) is often found in the literature (see Artl, Artlová, 2003; Kirchgässner and Wolters, 2006) as

$$
\sigma_{t}^{2}=\alpha_{0}+\sum_{i=1}^{q} \alpha_{i} \epsilon_{t-i}^{2}+\sum_{j=1}^{p} \beta_{j} \sigma_{t-j}^{2}
$$

where $\epsilon_{t}=e_{t} \sigma_{t}$, with $e_{t}$ as above. One can consider more regressors in the conditional mean equation as well (in our case, we will fit ARMA or AR models). For example, when considering a $\operatorname{GARCH}(1,1)$ with an $\mathrm{AR}(1)$ regressor in a mean equation, one gets

$$
\begin{gathered}
X_{t}=\alpha X_{t-1}+\epsilon_{t} \\
\sigma_{t}^{2}=\alpha_{0}+\alpha_{1} \epsilon_{t-1}^{2}+\beta_{1} \sigma_{t-1}^{2}
\end{gathered}
$$

Characteristic of a heteroscedastic hydrological model error time series is so-called volatility clustering. Volatility is another name for a time-varying variance. Volatility clustering means that small changes imply small changes and that a high variance "in forecasting will be sustained over a period before it dies away" (Fan and Yao 1995, see also Fig. 2). Furthermore, one can often speak of a leverage effect, which means that the variance reacts more strongly to negative shocks than to positive ones. This asymmetrical effect is not in accord with the original GARCH model, and there are several variations designed to handle this effect, e.g., the exponential GARCH model, which will be used here.

Here, the variance equation is defined over the $\ln \left(\sigma_{t}^{2}\right)$ values; thus one does not have any restrictions on the positivity of the parameters. The variance equation of a $\operatorname{EGARCH}(1,1)$ model is defined as follows:

where

$$
\ln \left(\sigma_{t}^{2}\right)=\alpha_{0}+\alpha_{1} g\left(e_{t-1}\right)+\beta_{1} \ln \left(\sigma_{t-1}^{2}\right)
$$

$$
g\left(e_{t-1}\right)=\delta_{1} e_{t-1}+\gamma_{1}\left(\left|e_{t-1}\right|-E\left|e_{t-1}\right|\right)
$$

Since $e_{t}$ is a sequence of i.i.d $(0,1), g\left(e_{t}\right)$ is uncorrelated with a 0 mean. Furthermore, if one rewrites $g\left(e_{t}\right)$ as

$$
g\left(e_{t}\right)= \begin{cases}\left.\delta_{1} e_{t}+\gamma_{1}\left(e_{t}\right)-\gamma_{1} E\left|e_{t}\right|\right) & \text { if } e_{t}>0 \\ \left.\delta_{1} e_{t}-\gamma_{1}\left(e_{t}\right)-\gamma_{1} E\left|e_{t}\right|\right) & \text { if } e_{t}<0\end{cases}
$$


One can see that the $g\left(e_{t}\right)$ function models the different effect of positive and negative shocks on the logarithm of the variance. If $\gamma_{1}=0$, one cannot speak of a different effect of a greater effect of positive or negative changes in the errors on the variance, $\gamma_{1}>0$ represents the leverage effect.

\subsection{Data analysis}

The actual data analysis was arranged as follows (some details on the methods are given below):

1. We estimated the basic descriptive statistics of the data and removed the deterministic components, i.e., the trend and cyclical components (seasonality was explicitly not considered in the model error time series).

2. We tested the stationarity using the ADF test and fitted an appropriate ARMA model on the residuals.

3. Then we examined the residuals for possible heteroscedasticity by viewing the ACF of the squared residuals and conducting the ARCH LM test. Subsequently, we fitted a GARCH-type model and examined the fit and residuals.

4. We provided a further analysis by comparing the performances of the one-step-ahead forecasts of the models obtained using the MDM test and the Nash-Sutcliffe coefficient.

A simple way of removing the trend component using regression was employed. For the removal of the cyclical components, spectral analysis methods were used. One assumes that the time series can be represented in means of

$$
X_{t}=\mu+\sum_{j=0}^{k}\left(\alpha_{j} \cos \left(\omega_{j} t\right)+\beta_{j} \sin \left(\omega_{j} t\right)\right)+\epsilon_{t}
$$

with $\omega_{j} \in[0,2 \pi]$ and finds all the significant frequencies $\omega_{i}$.

The Fisher test (Antoch, 1995) was used to determine the existence of cyclical components in the time series; if the hypothesis of the existence of cyclical components could not be rejected, it helped to determine the frequencies for which the cyclical components should be removed.

We needed to verify the stationarity, since it is assumed for ARMA models. There are several tests for determining the stationarity of time series (the so-called unit root tests), each having a slightly different null hypothesis; for the details, see, e.g., Artl and Artlová, 2003). We used the Augmented Dickey-Fuller test (ADF test) here.

The choice of the order of the ARMA model was based on the shape of the autocorrelation and partial autocorrelation functions (ACF and PACF) (e.g., Box and Jenkins, 1976). It may happen that several alternative parameters of a model seem acceptable. For this reason, the information criteria, which were based on comparing the residuals resulting from the different models, were designed (Artl and Artlová, 2003). The most often used are the Akaike and Schwarz Bayes Information criteria (AIC/BIC), which were used here. A model with the minimum information criterion value was chosen, since all their definitions are based on comparing the maximum values of the log-likelihood function used when estimating the model parameters.

To test for the existence of heteroscedasticity, the ACF and PACF of the squared residuals were examined, and the LjungBox-Pierce Q-test was used on them to obtain the first estimate. To verify it, we used Engle's Langrange multiplier ARCH test (ARCH LM test). The use of this test is motivated by a fact which has especially been found with financial heteroscedastic time series. It has been observed that "the magnitude of residuals ap- peared to be related to the magnitude of recent residuals" (Engle, 1982; Eviews, 2002).

In order to check the goodness of fit of the estimated model, we checked if the residuals suffice a white noise process and especially examined their lack of correlation and the significance of the parameter estimates (Aas and X.K. Dimakos, 2004; Kirchgässner and Wolters, 2006). Considering the first issue, we visually examined the autocorrelation function, and, as, a more formal test, the Ljung-Box-Pierce Q-test was also applied. For the latter, we used the coefficient tests listed in Eviews (2002). In our case, we also tried to verify the models by examining their forecasting performance.

In our case, we were more interested in the values of the actual forecasted time series; thus we did not go into detail considering the volatility forecasts. When constructing forecasts of the mean equation, there are several possible methods, for example, a method based on transferring the autocovariance matrix on the time series "into the future" as described in (Brockwell and Davis, 1998). Given the hydrological context of the forecasting exercise, we used the "naive" method, described, for example, in Artl and Artlová (2003). Here, one computes the expected conditional value $\mathrm{E}\left(\mathrm{X}_{\mathrm{T}+\mathrm{h}} \mid \Omega_{\mathrm{T}}\right)$, where $\mathrm{h}$ is the forecast horizon, $\mathrm{T}$ is the threshold of the prediction, and $\Omega_{\mathrm{T}}$ is the known past, since, as can be shown, this is the value with the minimum squared error.

We compared the predictions produced by GARCH-type models against an ARMA-type model. As the criterion, we used the modified Diebold-Mariano statistics (Diebold and Mariano, 1995; Harvey et al., 1997); the details of the test are also given in Komorník et al., (2006). The comparisons between the distinct models were given in the form of a result table; the entries have 3 possible values: 0 , when the models statistically have the same performance; 1, when model A delivers a statistically significant better performance than $\mathrm{B}$; and -1 , when model A delivers a statistically significant worse performance than B (for more details on the test, see, e.g., Komorník et al., (2006).

The Nash-Sutcliffe coefficient, which is the most popular model performance criterion in hydrology, was also used. It can be written as

$$
N S=1-\frac{\sum_{i=1}^{n}\left(Q_{o b s_{i}}-Q_{c o m p}\right)^{2}}{\sum_{i=1}^{n}\left(Q_{o b s_{i}}-\overline{Q_{o b s}}\right)^{2}}
$$

where $\mathrm{n}$ denotes the number of observations; $\mathrm{Q}_{\mathrm{obs}} ; \mathrm{Q}_{\text {comp }}$ stand for the measured and forecasted flow values, respectively, and $\bar{Q}_{\mathrm{obs}}$ is the sample mean. This number compares the model forecasts with the alternative that the next value would be approximated by the sample mean (of the forecasted period). Values close to 0 indicate that the fit of the model is no better than using just the sample mean; values close to 1 indicate a good performance.

\section{THE PILOT SITES AND DATA}

The lower Morava river is a typical alluvial river. It is located in western Slovakia and constitutes the border with Austria (see Fig. 3). The reach between Moravský Svätý Ján and Záhorská Ves with a length of $34.76 \mathrm{~km}$ and a slope of $0.2 \%$ was chosen. There are two significant measured inflows, i.e., the Zaya and the Rudava Rivers, in the reach. The unmeasured lateral inflow in the whole reach had to be estimated from the known discharges of these two tributaries by hydrological analogy. For basic hydrological forecasting, a daily time step is sufficient. The measured daily flow data and outputs from the KLN flow routing model at the Záhorská Ves station were also selected as a basis for analysis. The KLN simulation error series for time series analysis and time 


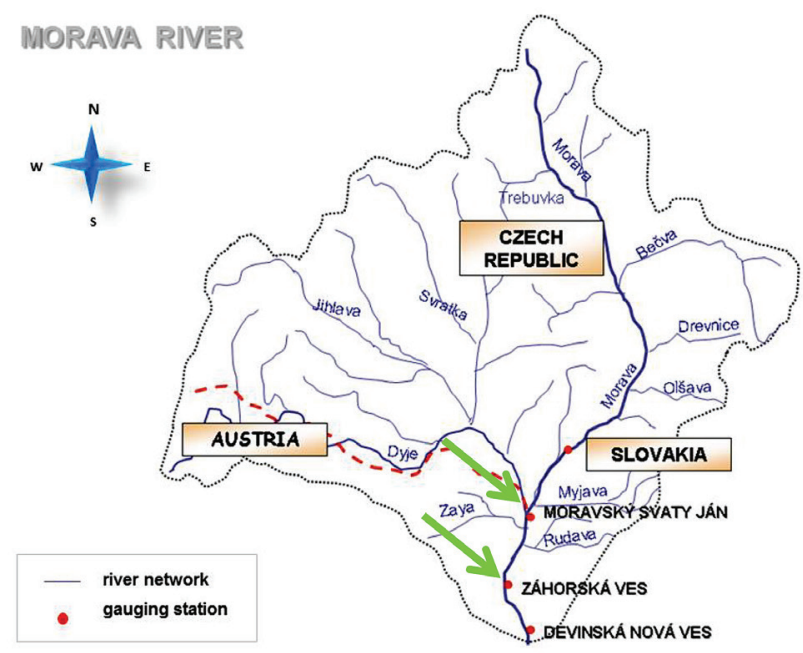

Fig. 3 The Morava River basin.

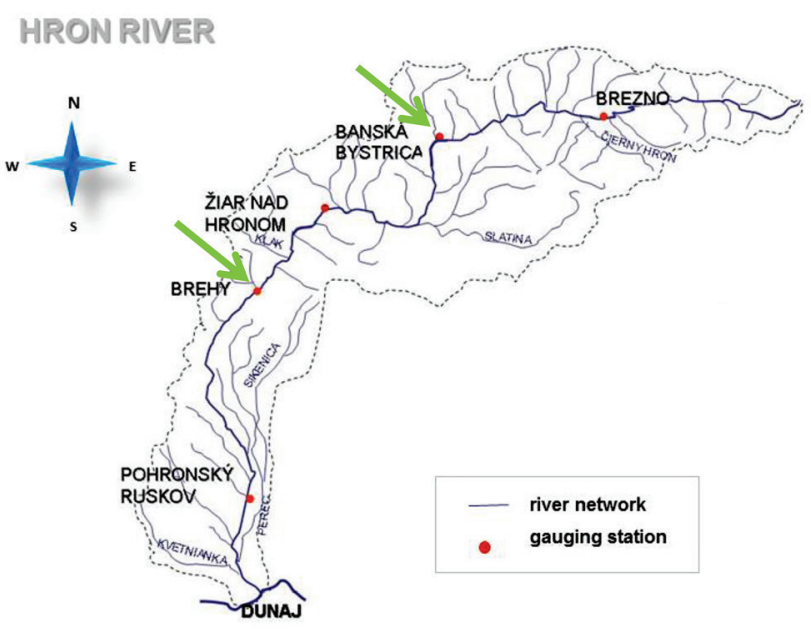

Fig. 4 The Hron River basin.

series model fitting was generated using 4 years of daily data of the Morava River for the period 1.11.1992 - 31.10.1996. The subsequent hydrological year was used for comparing the forecasting performance of the fitted time series models.

The Hron river springs at the base of the Lower Tatras; with its length of $298 \mathrm{~km}$, it is the second longest river in Slovakia (see Fig. 4). ). Its basin has a size of $5465 \mathrm{~km}^{2}$ and thus covers $11 \%$ of the area of Slovakia. In the upper mountain regions rainfall runoff processes dominate the flow regime. Flash floods from convective events represent a threat to local villages lying in narrow valleys, and rainfall of a cyclonic origin represents the main danger to major towns and industrial areas along the main river. In the lower part of the catchment, runoff concentration and routing dominate the flow processes. Therefore, flow-routing modelling with daily time steps is important in forecasting studies. The reach between Banská Bystrica and Brehy was chosen. The measured flow data and outputs from the KLN multilinear model for the Brehy station (where the river starts to have an alluvial character) will be analyzed here. We used the time period 1.11.1991 - 30.10.1995 for generating the KLN model simulation error series and fitting the time series models; we then compared the forecasting performance of these models in the subsequent hydrological year.

\section{RESULTS}

In this section, we present the results of the model error time series analysis. There are two differences in the actual analysis of these data, which need to be considered compared to the analysis of a natural hydrological series:

1. The model error time series takes all possible values, not only positive numbers, so no initial transformation of the data is needed.

2. There is no physical justification for assuming seasonal dependencies within the series. The model errors depend much more on the inadequate description of the modelled process within the conceptual model and the inputs. Large errors can occur at any time. For this reason, we only analyzed the cyclical components in two alternatives, i.e., including and excluding the removal of the cyclical components. We will denote the version of a model where we removed the cyclical component as "-C".

Table 1 contains the descriptive statistics of the error series for both rivers. The data are skewed, display excess kurtosis, and are strongly autocorrelated.

Tab. 1: Descriptive statistics, KLN model simulation error time series, $\mathrm{m}^{3} / \mathrm{s}$.

\begin{tabular}{|l|c|c|}
\hline & Morava & Hron \\
\hline Observations & 1461 & 1461 \\
\hline Mean $\left[\mathrm{m}^{3} / \mathrm{s}\right]$ & -2.458704 & 1.475892 \\
\hline Median $\left[\mathrm{m}^{3} / \mathrm{s}\right]$ & -1.890653 & 1.287106 \\
\hline Maximum $\left[\mathrm{m}^{3} / \mathrm{s}\right]$ & 44.84309 & 99.12368 \\
\hline Minimum $\left[\mathrm{m}^{3} / \mathrm{s}\right]$ & -85.75365 & -188.5240 \\
\hline St. Deviation $\left[\mathrm{m}^{3} / \mathrm{s}\right]$ & 7.547681 & 18.46733 \\
\hline Skewness $[-]$ & -1.541635 & -1.544301 \\
\hline Kurtosis $[-]$ & 29.53399 & 17.62824 \\
\hline
\end{tabular}

\subsection{The Morava River error series}

We analysed the data and fitted the models on 4 years of daily KLN model simulation error data of the Morava River for the period 1.11.1992 - 31.10.1996 (November is the first month of the hydrological year). A slight trend was detected. We used the Fisher test to find the significant frequencies of the cyclical component. The fitted coefficients can be found in Table 2. The Fisher test returned 13 significant values. Most of the values correspond to shorter time periods of approximately 1 month, except for the 365.25 day period. This is different compared to the natural data, where the majority of the frequencies would correspond to time spans longer than 1 year.

We analyzed removing the cyclical components one after another and compared the AIC/BIC values for an AR model fitted to the data. Generally speaking, the AIC/BIC values pointed to an improvement in fit with the increasing number of the removed components. In both cases (removing/not removing the cyclical components), we decided to fit an AR(3) model on the 
Tab. 3: Performance comparison based on MDM test - the Morava error series

\begin{tabular}{|c|c|c|c|c|}
\hline & AR(3) & AR(3) - C & EGARCH (1.1) & EGARCH (1.1) - C \\
\hline \hline $\operatorname{AR}(3)$ & $\mathrm{X}$ & 1 & 0 & 0 \\
\hline $\mathrm{AR}(3)-\mathrm{C}$ & -1 & $\mathrm{X}$ & 0 & 0 \\
\hline EGARCH (1.1) & 0 & 0 & $\mathrm{X}$ & 1 \\
\hline EGARCH (1.1) - C & 0 & 0 & -1 & $\mathrm{X}$ \\
\hline
\end{tabular}

Tab. 2: Trend and cyclical components, Morava error series.

\begin{tabular}{|c|c|c|}
\hline \multirow{3}{*}{$\begin{array}{l}\text { Trend } \\
\text { Cyclical component } \\
\text { Period }\end{array}$} & \multicolumn{2}{|c|}{$-0.002812 t-0.425144$} \\
\hline & \multicolumn{2}{|c|}{ Regression parameters } \\
\hline & $\cos (2 \pi /$ period $)$ & $\sin (2 \pi /$ period $)$ \\
\hline 32.4667 & 0.060158 & 0.185916 \\
\hline 23.5645 & -0.228330 & -0.108508 \\
\hline 22.4769 & -0.146077 & -0.053499 \\
\hline 365.25 & 0.929772 & -0.576626 \\
\hline 27.566 & 0.111312 & 0.121599 \\
\hline 44.2727 & -0.221518 & -0.420939 \\
\hline 23.9508 & 0.064123 & -0.132150 \\
\hline 31.7609 & 0.283254 & -0.523426 \\
\hline 22.1364 & 0.192058 & -0.057147 \\
\hline 97.4 & 0.207627 & 0.089738 \\
\hline 29.8163 & 0.145436 & -0.016418 \\
\hline 25.1897 & -0.031744 & 0.208416 \\
\hline 34.7857 & -0.291777 & 0.072483 \\
\hline
\end{tabular}

residuals. When examining the ACF of the residuals, they were not completely uncorrelated after the AR(3) fit. The time series also showed the presence of heteroscedasticity after the AR fit. The originally considered GARCH $(1,1)$ model was not usable on either of the data sets. The ACF of the residuals improved after fitting the EGARCH model. The only case where the residuals were completely uncorrelated was the EGARCH - C model.

The forecasting performance was compared using 4 models, i.e., the $\operatorname{AR}(3)$ and $\operatorname{AR}(3)-\operatorname{EGARCH}(1,1)$ models with and without removing the cyclical components. The results of the MDM test can be found in Table 3; the NS values are listed in Table 4. Here, the two tests delivered slightly different results. The NS coefficients indicated the better forecasting performance of the EGARCH $(1,1)$ over the other two models. However, the MDM test considered the EGARCH and AR(3) to be statistically equivalent. The models which did not have the cyclical component removed performed better.

\subsection{The Hron River Error series}

Using an analogous procedure as in the previous section, we used the daily data of the KLN simulation error series for measuring the Brehy station from the time period 1.11.1991 - 30.10.1995 for the model fitting and produced/compared the forecasts for the subsequent year. The trend and cyclical component analysis, which is listed in Table 5, showed similarly interpretable results as in the Morava error series. When fitting the baseline ARMA type
Tab. 4: NS coefficients for the Morava error series

\begin{tabular}{|c|l|}
\hline $\operatorname{AR}(3)$ & 0.8927 \\
\hline $\operatorname{AR}(3)-\mathrm{C}$ & 0.8485 \\
\hline EGARCH (1.1) & 0.9371 \\
\hline EGARCH (1.1) -C & 0.9168 \\
\hline
\end{tabular}

model in the case of the Brehy error series dataset, it turned out that different ARMA models were suitable for the versions with/ without the cyclical component removed. Otherwise, the analysis yielded similar results as in the previous section. Removing the cyclical components followed the same pattern as in the Morava errors data set when analysing the AIC and BIC values. We decided for an AR(3) model when considering the "not-removing cyclical components" variant and for an ARMA(1,1) model in the other case. This was obviously based on the change in the structure of the ACF and PACF after removing the cyclical components. Again, the ARCH LM test rejected the hypothesis of no heteroscedasticity, and it was not possible to fit the traditional GARCH model (for similar reasons, i.e., either the algorithm did not terminate or the fitted coefficients were negative, which contradicts the definition). Thus we fitted an $\operatorname{EGARCH}(1,1)$ model on the residuals after the $\operatorname{AR}(3)$ and $\operatorname{ARMA}(1,1)(-\mathrm{C})$ models. The $\operatorname{ARMA}(1,1)$ residuals were statistically uncorrelated; the subsequent EGARCH fit actually made the ACF worse. On the other hand, fitting the EGARCH on the $\mathrm{AR}(3)$ residuals resulted in a statistically zero ACF and PACF.

Tab. 5: Trend and cyclical components, Hron error series

\begin{tabular}{|c|c|c|}
\hline & \multicolumn{2}{|c|}{ Brehy } \\
\hline Trend & \multicolumn{2}{|c|}{$0.000115 \mathrm{t}-3.262928$} \\
\hline Cyclical component & \multicolumn{2}{|c|}{ Regression parameters } \\
\hline Period & $\cos (2 \pi /$ per. $)$ & $\sin (2 \pi /$ per. $)$ \\
\hline 132.82 & -2.383289 & 3.784694 \\
\hline 121.75 & -0.775915 & 3.108622 \\
\hline 365.25 & -2.838499 & -0.670029 \\
\hline 146.1 & -2.416026 & 0.323053 \\
\hline 292.2 & -3.600949 & 1.185945 \\
\hline 208.71 & 1.827090 & 1.474034 \\
\hline 85.94 & 2.383077 & -2.048314 \\
\hline 104.36 & -1.451426 & -2.068561 \\
\hline 182.625 & -0.173528 & -1.789962 \\
\hline 97.4 & -2.913911 & -2.834417 \\
\hline
\end{tabular}


Tab. 6: Performance comparison based on MDM test - the Hron error series

\begin{tabular}{|l|c|c|c|c|}
\hline & AR(3) & ARMA(1,1)-C & AR(3)-EGARCH (1.1) & $\begin{array}{c}\text { ARMA( 1,1) - } \\
\text { EGARCH (1.1) -C }\end{array}$ \\
\hline AR(3) & X & 1 & -1 & -1 \\
\hline ARMA(1,1)-C & -1 & $X$ & -1 & -1 \\
\hline AR(3)-EGARCH (1.1) & 1 & 1 & $X$ & 0 \\
\hline ARMA( 1,1$)-$ EGARCH (1.1)-C & 1 & 1 & 0 & $X$ \\
\hline
\end{tabular}

Tab. 7: NS coefficients for the Hron error series

\begin{tabular}{|l|l|}
\hline AR(3) & 0.9217 \\
\hline ARMA $(1,1)-C$ & 0.8449 \\
\hline AR(3) - EGARCH (1.1) & 0.9769 \\
\hline ARMA( 1,1$)-$ EGARCH (1.1) -C & 0.9807 \\
\hline
\end{tabular}

In the comparison of the forecasting performance of the Brehy error series models, according to the MDM tests (Tables 6), the $\operatorname{AR}(3)-\operatorname{EGARCH}(1,1)$ and $\operatorname{ARMA}(1,1)-\operatorname{EGARCH}(1,1)-\mathrm{C}$ were equivalent in performance. They both outperformed the $\operatorname{AR}(3)$ model. The ARMA $(1,1)$ was the worst performing model in the test. The NS coefficients (Table 7) confirmed these results by giving a slight advantage to the $\operatorname{ARMA}(1,1)-\mathrm{EGARCH}(1,1)-\mathrm{C}$ model.

\section{DISCUSSION}

In general, heteroscedasticity was present in both data sets. The GARCH-type model proved to be well suited for removing it in all the cases. However, the GARCH model (tested here with the t-distribution) in its original form was not generally applicable; we had to use the EGARCH $(1,1)$ model instead. Unlike in econometric time series, here the $\gamma$ parameter was positive, which means that the data tended to react more strongly to positive changes, rather than to negative ones. In this particular case the general property of hydrological processes is that the rise of a discharge is rainfall/snowmelt driven and that the decrease in a discharge is ruled by the storage in the driven system (catchment or river reach), which filters and smoothes the pulse-like behaviour of the inputs. The analysis also showed that this behaviour is present in the hydrological model error series, which can be explained by the fact that the modelling and forecasting of floods is a more demanding task than that of low flows.

This result is of particular importance with respect to error time series of hydrological models. It underpins the need for a non-mechanistic approach in the case-based analysis of such data and the physical interpretation of statistical modelling results. However, in the case of hydrological data, they also imply that a pure GARCH may not be the best choice (because of the special structural character of the error series data) and that the use of the EGARCH type of models should be further explored. The usefulness of using EGARCH instead of GARCH has not been considered thus far in the hydrological literature, and other approaches were chosen instead, e.g., Elek, P. and Márkus, L. (2008), who tried to overcome the fitting problems by mathematical modifications of the GARCH model.

For the hybrid framework, comparisons with ARMA models were considered as well for the modelling of error series, although the ARMA models may not properly reflect the structural properties of the heteroscedastic error series and may outperform the GARCH-type models in their practical performance. Indeed, as reported in the econometric literature, when considering the MDM test, the EGARCH model showed a better performance only on the Brehy data; otherwise, the forecasting performances were statistically equivalent with the respective ARMA models.

To improve the heteroscedastic model's performance, the need to conduct standard time series analysis, i.e., to consider cyclical components in the error series, was questioned. In all cases, not removing the cyclical components improved the model's forecasting performance, which confirmed the hypothesis, for no logical reason, as to why the error series should show cyclical behaviour. These results can be recommended to be followed in the setup of practical hybrid modelling frameworks and can be seen as a contribution to the development of such systems, which seem to be gaining increased popularity in hydrology. The cyclicity in the error series may possibly mask the inherent heteroscedasticity in the data which, however, should be properly considered in the modelling by a GARCH-type of model.

\section{CONCLUSIONS}

Thus far, only relatively few attempts to apply various nonlinear time series models have been reported in the hydrological time series literature. The fitting, forecasting and simulation performance of such models have to be explored on a case-bycase basis. This study presents results concerning the possibility of using GARCH-type models for such purposes. The innovative aspect of their application here was the development of nonlinear time series models for hybrid modelling frameworks. The hybrid modelling framework was created by analyzing the structure of the error series of the KLN deterministic multilinear flow routing model and forecasting these by various time series models. This approach allows for the improvement of the overall forecasting performance of the hydrological model. The investigation of the various time series model properties and performances was thoroughly tested on two river reaches in Slovakia.

As an overall recommendation for practical application, the EGARCH class of models seems to promise great potential for forecasting hydrological model error series. This potential should be further explored in the simulation of natural hydrological series, which may better prove the adequacy of this model type for a broader range of hydrological applications. The question as to whether such models may reproduce the characteristic statistical properties of annual and monthly data when aggregating them from daily series and if they can preserve the behaviour of extreme values constitutes an interesting challenge for future research.

\section{Acknowledgement}

The authors gratefully acknowledge the VEGA Grant Agency Commission for its support of the Project No. 1/0891/17. 


\section{REFERENCES}

Aas, K. - Dimakos, X.K. (2004) Statistical modelling of financial time series: An introduction, Norwegian Computing Center.

Amendola, A. (2003) Forecasting performance of regime switching models in hydrological time series. Giornata di Studio: Metodi Statistici e Matematici per le Analisi Idrologiche- Roma, CNR-GNDCI.

Antoch, J. (1995) Critical values of Fisher's and Siegel's test, Kybernetika 31, No. 4, pp. 385-393.

Arduino, G. - Reggiani, P. - Todini, E. (2005) Recent advances in flood forecasting and flood risk assessment, Hydrology and Earth System Sciences 9, No. 4, pp. 280-284.

Artl, J. - Artlová, M. (2003) Finanční časové rady. Vlastnosti, metody modelování, př́klady, aplikace (Financial time series. Properties, modelling methods, examples and applications), Grada, Prague.

Bollerslev, T. - Engle, R. F. - Wooldridge, J. M. (1988) A capital asset pricing model with time varying covariances, Journal of Political Economy, Vol. 96, No. 1 (Feb., 1988), pp. 116-131.

Box, G.E.P. - Jenkins, G.M. (1976) Time series analysis forecasting and control, Holden-Day, San Francisco.

Brockwell, P. - Davis, R.A. (1998) Time series: Theory and methods, Springer.

Chen, C. H. - Liu, C. H. - Su, H. C. (2008) A nonlinear time series analysis using two-stage genetic algorithms for streamflow forecasting, Hydrological Processes, Vol. 22, No. 18, pp. 3697-3711.

Chin-Hui L. - Chang-Shian Ch. (2007) "Using two-stage genetic algorithms to solve the nonlinear time series models for tenday streamflow forecasting," 2007 IEEE Congress on Evolutionary Computation, Singapore, pp. 4365-4371. doi: 10.1109/ CEC.2007.4425041.

Danáčová, M. - Szolgay, J. (2007) K určovaniu vzt’ahu medzi prietokom a postupovou dobou povodni na hornom Hrone pomocou multilineárneho modelu (On the estimation of the relationship between discharge and travel time using a multilinear model in the Upper Hron catchment). Acta Hydrologica Slovaca. Vol. 8, No. 2, pp.135-139 (in Slovak).

Danáčová, M. (2008) Multilineárne modelovanie transformácie prietokových vln. (Multilinear modeling of flood routing), Ph.D. thesis, Slovak University of Technology, Bratislava (in Slovak).

Diebold, F.X. - Mariano, R.S. (1995) Comparing predictive accura$c y$, Journal of Business and Economic Statistics 13, pp. 253-263.

Elek, P. - Márkus, L. (2008) A light-tailed conditionally heteroscedastic model with applications to river flows. Journal of Time Series Analysis, 29: 14-36. doi:10.1111/j.1467-9892.2007.00542.x

Engle, R. F. (1982) Autoregressive conditional heteroscedasticity with estimates of variance of United Kingdom inflation, Econometrica, 50, pp. 987-1008.

Eview 4 (2002) User's Guide, Quantitative Micro Software, LCC, 1994-2002.

Fan, J. - Yao, Q. (1995) Nonlinear time series (nonparametric and parametric methods), Springer Science+Business Media, Inc., New York.
Fendeková, M. - Pekárová, P. - Fendek, M. - Pekár, J. - Škoda, P. (2014) Global drivers effect in multi-annual variability of runoff. Journal of Hydrology and Hydromechanics, 62(3), pp. 169-176.

Harvey, D.I. - Levbourne, S.J. - Newbold, P. (1997) Testing the equality of prediction mean squared errors, International Journal of Forecasting 13 (1997), pp. 281-291.

Kirchgässner, G. - Wolters, J. (2006) Einführung in die moderne Zeitreihen-analyse, Verlag Vahlen, München.

Komorník, J. - Komorníková, M. - Mesiar, R. - Szökeová, D. - Szolgay J. (2006) Comparison of forecasting performance of nonlinear models of hydrological time series. Physics and Chemistry of the Earth, Vol. 18, pp. 1127-1145.

Komorníková, M. - Szolgay J. - Svetlíková D. - Szökeová, D. Jurčák S. (2008) A hybrid modeling framework for forecasting monthly reservoir inflows. Journal of Hydrology and Hydromechanics, 56 (3), pp. 145-162.

Koutsoyiannis, D. (2005) The encyclopedia of water, ch. Stochastic simulation of hydrosystems, Wiley, New York.

Kraus, J.P. - Neuhaus, G. (2004) Einführung in die Zeitreihenanalyse, Springer Verlag, Berlin, Heilderberg.

Modarres, R. - Ouarda, T.B.M.J. (2013) Generalized autoregressive conditional heteroscedasticity modeling of hydrologic time series, Hydrological Processes, 27, pp. 3174-3191.

Modarres, R. - Ouarda, T.B.M.J. (2014) Modeling the relationship between climate oscillations and drought by amultivariate GARCH model, Water Resour. Res., 50, pp. 601-618, doi:10.1002/2013WR013810.

Moeeni, H. - Hossien B. - Fatemi, S.E. (2017) Stochastic model stationarization by eliminating the periodic term and its effect on time series prediction. Journal of Hydrology. Vol. 547 pp. 348-364.

Nelson D.B. (1991) Conditional heteroskedasticity in asset returns: a new approach. Econometrica, Vol. 59, No. 2, pp. 347-370.

Otache, M. - Ahaneku, I. - Mohammed, A. - Musa, J. (2012) "Conditional Heteroscedasticity in Streamflow Process: Paradox or Reality?” Open Journal of Modern Hydrology, Vol. 2 No. 4, 2012, pp. 79-90. doi: 10.4236/ojmh.2012.24010.

Pappenberger, F. - Beven, K. J. - Hunter, N. M. - Bates, P. D. Gouweleeuw, B. T. - Thielen, J. - de Roo, A. P. J. (2005) Cascading model uncertainty from medium range weather forecasts (10 days) through a rainfall-runoff model to flood inundation predictions within the European Flood Forecasting System (EFFS), Hydrology and Earth System Sciences 9, pp. 381-393.

Pekárová, P. - Onderka, M. - Pekár, J. - Rončák, P. - Miklánek, P. (2009) Prediction of Water Quality in the Danube River Under extreme Hydrological and Temperature Conditions. Journal of Hydrology and Hydromechanics, Vol. 57, No. 1, pp. 3-15.

Salas, J.D. - Delleur, J.W. - Yevjevich, V. - Lane W.L. (1980) $A p$ plied modeling of hydrologic time series, Water Resources Publications. 
Srikanthan, R. - McMahon, T.A. (1980) Stochastic generation of annual streamflows, Journal of the Hydraulics Division 12, 2011 - 2028.

Svetlíková, D. (2008) Hybridné metódy v hydrologických predpovediach (Hybrid methods in hydrological forecasting), Ph.D. thesis, Slovak University of Technology, Bratislava (in Slovak).

Szolgay, J. (1985) Predpoved' transformácie prietokovej vlny stochasticko - štrukturálnym modelom (Forecast of a discharge wave transformation by a stochastic-structural model), In: II. Cs. hydrologické dni, Košice, pp. 245 - 251 (in Slovak).

Szolgay, J. - Danáčová, M. - Jurčák, S. - Spál, P. (2008) Multilinear flood routing using empirical wave-speed discharge relationships: case study on the Morava river. Journal of hydrology and hydromechanics, Vol. 56, No. 4, pp. 213-227.

Szolgay, J. - Danáčová, M. - Papanková, Z. (2006) Case study of multilinear flood routing using empirical relationships between the flood wave speed and the discharge. Slovak Journal of Civil Engineering. Vol. 14, No. 1, pp. 1-9.

Szolgay, J. - Minárik, B. (1992) Adaptive Fehlerkorrektur mittels eines self - tuning Predictors, In: Konferenzbericht, XVI. Konferenz der Donauländer uber hvdrologische Vorhersagen und hvdrologisch- wasserwirtschaftliche Grundlagen, Koblenz, NKBD IHP UNESCO, pp. 78 - 82.

Szolgay, J. (2004) Assessment of the impacts of land-use and climate changes. Hydrological Risk: Recent advances in peak river flow modelling, prediction and real-time forecasting (et al. A. Brath, ed.), BIOS, Castrolibero, 2004, pp. 271 - 284.

Szolgayova, E. - Laaha, G. - Blöschl, G. - Bucher C. (2014) Factors influencing long range dependence in streamflow of European rivers, Hydrological Processes, Vol. 28, No. 4, pp. 1573-1586

Tamea, S. - Laio, F. - Ridolf, L. (2005) Probabilistic nonlinear prediction of river flows. Water Resources Research, Vol. 41, W09421.
Todini, E. (2004) Role and treatment of uncertainty in real-time flood forecasting. Hydrological Processes, Vol. 18, No. 14, pp. 2743 2746.

Tol, R.S.J. (1996) Autoregressive conditional heteroscedasticity in daily temperature measurements. Environmetrics, Vol. 7, No. 1, pp. 67-75. doi:10.1002/(SICI)1099-095X(199601)7:1<67::AIDENV164>3.0.CO;2-D

Valent, P. - Howden, N. - Szolgay, J. - Komorníková, M. (2011) Analysis of Nitrate Concentrations Using Nonlinear Time Series Models. Journal of Hydrology and Hydromechanics, Vol. 59, No. 3, pp. 157-170.

Valipour, M. - Banihabib, M.E. - Behbahani, S.M.R. (2013) Comparison of the ARMA, ARIMA, and the autoregressive artificial neural network models in forecasting the monthly inflow of Dez dam reservoir. Journal of Hydrology, Vol. 476, pp. 433-441.

Valipour, M. (2015) Long-term runoff study using SARIMA and ARIMA models in the United States. Meteorological Application, Vol. 22 , No. 3, pp. 592-598.

Wang W. - Vrijling J.K. - Van Gelder P.H.A.J.M. - Ma J. (2006) Testing for nonlinearity of streamflow at different timescales. Journal of Hydrology, Vol. 322, Nos. 1-4, pp. 247-268.

Wang, W.C. - Chau, K.W., Xu, D.M. - Chen, X.Y. (2015) Improving forecasting accuracy of annual runoff time series using ARI$M A$ based on EEMD decomposition. Water Resources Management 29(8), 2655-2675.

Wang, W. - Van Gelder, P. H. A. J. M. - Vrijling, J. K. - Ma, J. (2005) Testing and modelling autoregressive conditional heteroskedasticity of streamflow processes, Nonlin. Processes Geophys., Vol. 12, pp. 55-66. 